\title{
Preparation and Characterization of Groundnut Shell-Based Activated Charcoal
}

\author{
*AJALA, LO; ALI, EE \\ Department of Science Laboratory Technology, Akanu Ibiam Federal Polytechnic, Unwana, Nigeria \\ ${ }^{*}$ Corresponding author: loajala@akanuibiampoly.edu.ng; Tel: +2348035904999
}

\begin{abstract}
Groundnut shell, an agricultural waste was used as a precursor for the preparation of activated charcoal using zinc chloride as a chemical activating agent. The results of the optimization studies showed that the activated charcoal had best iodine adsorption capacity at $1.0 \mathrm{~mol} \mathrm{dm}^{-3}$ activator's concentration, 2:1 impregnation ratio, $70{ }^{\circ} \mathrm{C}$ impregnation temperature, $12 \mathrm{hr}$ impregnation time, $500{ }^{\circ} \mathrm{C}$ activation temperature, and $2 \mathrm{hr}$ activation time. The surface chemistry of the adsorbent was studied by Fourier transform infra-red spectroscopy and scanning electron microscopy-energy dispersive X-ray spectroscopy. The activated charcoal was found to contain porous structures with adsorption capacities significantly correlated with iodine value, porosity, and surface area. The surface morphology of the activated charcoal was altered as compared with the un-activated product, signifying that the adsorbent had been chemically modified. The disappearance of some functional groups and shift in some absorption bands were further indication that surface structural modification took place during activation and carbonization. This research has revealed that groundnut shell could be employed for the production of an alternative adsorbent which can be utilize for filtration and detoxification of impure water, treatment of effluent and wastewater, adsorption of pesticides, heavy metals and dyes from aqueous media.
\end{abstract}

DOI: https://dx.doi.org/10.4314/jasem.v24i12.20

Copyright: Copyright (C) 2020 Ajala and Ali. This is an open access article distributed under the Creative Commons Attribution License (CCL), which permits unrestricted use, distribution, and reproduction in any medium, provided the original work is properly cited.

Dates: Received: 02 October 2020; Revised: 26 November 2020; Accepted: 12 December 2020

Keywords: Groundnut shell, activated charcoal, adsorbent, agricultural waste.

Activated charcoals are black solid substances resembling granular or powdered charcoal. They are economically produced by the activation and pyrolysis of renewable, readily available and cheaper carbonaceous precursors which are mainly industrial and agricultural by-products such as bagasse (Boonpoke et al., 2011), rice husk (Boonpoke et al., 2011; Ajala et al., 2020), coconut shell (Gawande and Kaware, 2017), sawdust (Alzaydien, 2016; Subramani and Revathi, 2015), empty palm fruit bunch (Hidayat and Sutrisno, 2017), physic nut waste (Elelu et al., 2019), pruning mulberry shoot (Wang et al., 2010), bamboo stem (Ijaola et al., 2013), chickpea (Özsin et al., 2019), acorn shell (Saka, 2012) and plant seeds (Mopoung et al., 2015; Sivakumar et al., 2012). The process produces a porous material with a large surface area (500-1500 $\mathrm{m}^{2} / \mathrm{g}$ ) (Wang et al., 2010) and a high affinity for organic compounds, chlorine, heavy metals, unpleasant tastes and odour in effluent or colour substances from gas or liquid streams. This is possible as a result of their highly developed pore structures and large internal specific surface area (Mansour et al., 2020; Wang et al., 2010; Hidayat and Sutrisno, 2017). However, the performance properties of activated charcoal dependlargely on the raw material source (Sivakumar et al., 2012). Adsorption of pollutants on activated charcoal has become acceptable as a result of its versatility, environmental compatibility, relative abundance and low-cost starting materials, usually, waste products, adsorption of a broad range of pollutants, fast adsorption kinetics, and ease of production (Mansour et al., 2020; Amirza et al., 2017; Reza et al., 2020). Activated charcoals had been used successfully in modern water treatment plants for water filtration and detoxification treatment of impure waters (Abraham et al., 2018; Jacob et al., 2017; Olagunju et al., 2015; Ijaola et al., 2013; Sivakumar et al., 2012), effluent and wastewater treatment (Tak et al., 2015; Yusufu et al., 2012; Marichelvan and Azhagurajan, 2018), adsorption of pesticide (Gokhale, 2020), dye adsorption (Wu et al., 2020; Mansour et al., 2020; Ani et al., 2020), heavy metal sorption from aqueous media (Ijaola et al., 2013; Mopoung et al., 2015; Elelu et al., 2019; Özsin et al., 2019; Ani et al., 2020), and prevention against novel Coronavirus (SARS-CoV-2) (Reza et al., 2020). Commercial activated charcoalsare expensive due to the use of non-renewable and relatively high-cost starting materials such as coal which are not suitable with respect to pollution control measure (Olagunju et al., 2015). In most developing countries, the demand for activated carbon is met by importation at exorbitant price, whereas there are vast industrial and agricultural by-products or wastes which can be used 
for its production to meet the local demands and even, for exportation. Recently, researchers had produced activated charcoals from renewable and cheaper precursors, which were mainly industrial and agricultural by-products. Despite extensive scientific researches on its production, there has been dearth of information with respect to its production from groundnut shell, hence, this study. This study was therefore aimed at producing and characterizing an activated charcoal from groundnut shell using $\mathrm{ZnCl}_{2}$ as the activating agent.

\section{MATERIALS AND METHODS}

Samples' Collection and Preparation: Groundnut shells were collected from the processing plant at Abakaliki, Nigeria. They were transported to the Chemistry Research Unit of the Department of Science Laboratory Technology, Akanu Ibiam Federal Polytechnic, Unwana, Nigeria. Extraneous materials were removed and were repeatedly washed with deionised water to remove other impurities and then, sun-dried for 3 days. The dried sample was pulverized and particle sizes of 500 to $600 \mu \mathrm{m}$ were collected and stored in an air-tight container for further analyses. Commercial activated charcoal (Calgon carbon, F300) used as a control and other chemicals were of analytical grades and were sourced from $\mathrm{BDH}$ Chemicals Limited, UK.

Carbonization, Activation and Optimisation: Preparation and optimisation studies of the activated charcoal were performed according to our previous study (Olagunju et al., 2015) and method of Wang et al. (2010). Briefly, the raw material (groundnut shell) was fed into the reactor of a locally fabricated pyrolysis plant and carbonised at $400^{\circ} \mathrm{C}$ for $1 \mathrm{hr}$. After carbonization, it was removed, allowed to cool and pulverized. A portion of the char produced, groundnut shell charcoal (GSC) was impregnated with zinc chloride of varying concentrations $(0.5,1.0,1.5,2.0$, 2.5) $\mathrm{mol} \mathrm{dm}^{-3}$ at $1: 1,1: 2,1: 3,2: 1,3: 1 \mathrm{w} / \mathrm{v}$ precursor : $\mathrm{ZnCl}_{2}$ ratios for $6,12,18,24$, and $30 \mathrm{hr}$ at impregnation temperatures of $20,40,60,80,100{ }^{\circ} \mathrm{C}$ simultaneously. The slurries formed were carbonised in a muffle furnace (Fisher-Thermo Scientific, USA) at varying temperatures $(250,350,450,550,650){ }^{\circ} \mathrm{C}$ for $1.0,1.5,2.0,2.5,3.0 \mathrm{hr}$, after which they were removed and cooled in ice water bath. Excess water was drained out and allowed to stand at room temperature. The residual activating reagent $\left(\mathrm{ZnCl}_{2}\right)$ and surface ash were removed from the carbonised products with $0.10 \mathrm{~mol} \mathrm{dm}^{-3}$ hydrochloric acid. They were furthered washed and rinsed with doubledistilled deionised water to remove residual acid until $\mathrm{pH} \sim 7$ was achieved. They were oven-dried
(Gallenkamp, US) at $110{ }^{\circ} \mathrm{C}$ until constant weights were attained. The individual weight of groundnut shell activated charcoal (GAC) produced was taken and the yield calculated. Adsorption on iodine of the various activated charcoals with respect to activation concentration, impregnation ratio, impregnation temperature, impregnation time, carbonization temperature and carbonization time was investigated to determine the optimum conditions for the preparation of MAC.

Physical and Chemical Characterization: The unactivated groundnut shell charcoal (GSC) and the activated groundnut shell charcoal (GAC) were subjected to the appropriate physicochemical analyses. Carbon yields were calculated from the sample weights before and after activation to their initial weights. The physicochemical properties were determined according to the methods outlined by Boonpoke et al. (2011). Surface morphologies were examined with the aid of scanning electron microscope (Phenom ProX, Thermo Scientific) coupled with energy dispersive X-ray spectrometer (ED-XRS) for elemental compositions according to the manufacturer operation directive. The variations in the absorption bands of functional groups before and after the activation were studied with Fourier transform infra-red spectrometer (Carg 630, Agilent) in the range of $4000-400 \mathrm{~cm}^{-1}$ following manufacturer operation procedure.

\section{RESULTS AND DISCUSSION}

Optimization Studies: Several optimization studies were carried out to evaluate the un-activated groundnut shell charcoal (GSC) and the activated groundnut shell charcoal (GAC). The results of their characterization are list thus.

Effect of concentration of activating agent: The iodine adsorption capacity of GAC was carried out with various concentrations of $\mathrm{ZnCl}_{2}$ solution. Before the optimum value, the iodine number was lowered. This could be due to insufficient activating agent to create more internal pore structures in the precursor. The optimum value (1004 mg gm ${ }^{-1}$ ) of iodine adsorption of the test adsorbent was reached at a corresponding concentration of $1.0 \mathrm{~mol} \mathrm{dm} \mathrm{dm}^{-3}$ (Fig. 1a). At this concentration, a higher reaction could have occurred leading to the release of more volatiles with the resultant affinity for more iodine molecules (Mopoung et al., 2015, Saka, 2012). Further increase in the concentration of $\mathrm{ZnCl}_{2}$ led to a progressive decrease in iodine adsorption capacity. This could be attributed to the collapse of micro-porous structures of the carbon 
as a result of excessive activation (Mopoung et al., 2015).

Effect of impregnation ratio: The variation in iodine number of the activated charcoal under test versus the impregnation ratio is shown in Figure 1b. At a constant precursor weight, there was an increase in the iodine numbers with concomitant increase in the volume of the activator until an optimum value was reach at the ratio of 2:1 (activator :precursor). The increase in iodine number could be linked to the reaction facilitating the release of volatiles in the carbon while creating porous structures (Mopoung et al., 2015; Saka, 2012) in the adsorbent. Thereafter, the iodine number sharply dropped as the weight of the precursor increased. This could be credited to an insufficient activator to react with the precursor.

Effect of impregnation temperature: The impregnation temperature is known to influence the pore structure of activated charcoal with respect to adsorption capacity (Wang et al., 2010). The iodine numbers increased gradually with the temperature of impregnation. Equilibrium was attained when the temperature was extended to $70{ }^{\circ} \mathrm{C}$ (Fig. 1c). As the temperature was increased beyond the critical value, iodine number was observed to decrease gradually. This could be as a result of expansion of micro-pores and collapse of pore walls leading to the release of more volatile components (Mopoung et al., 2015).
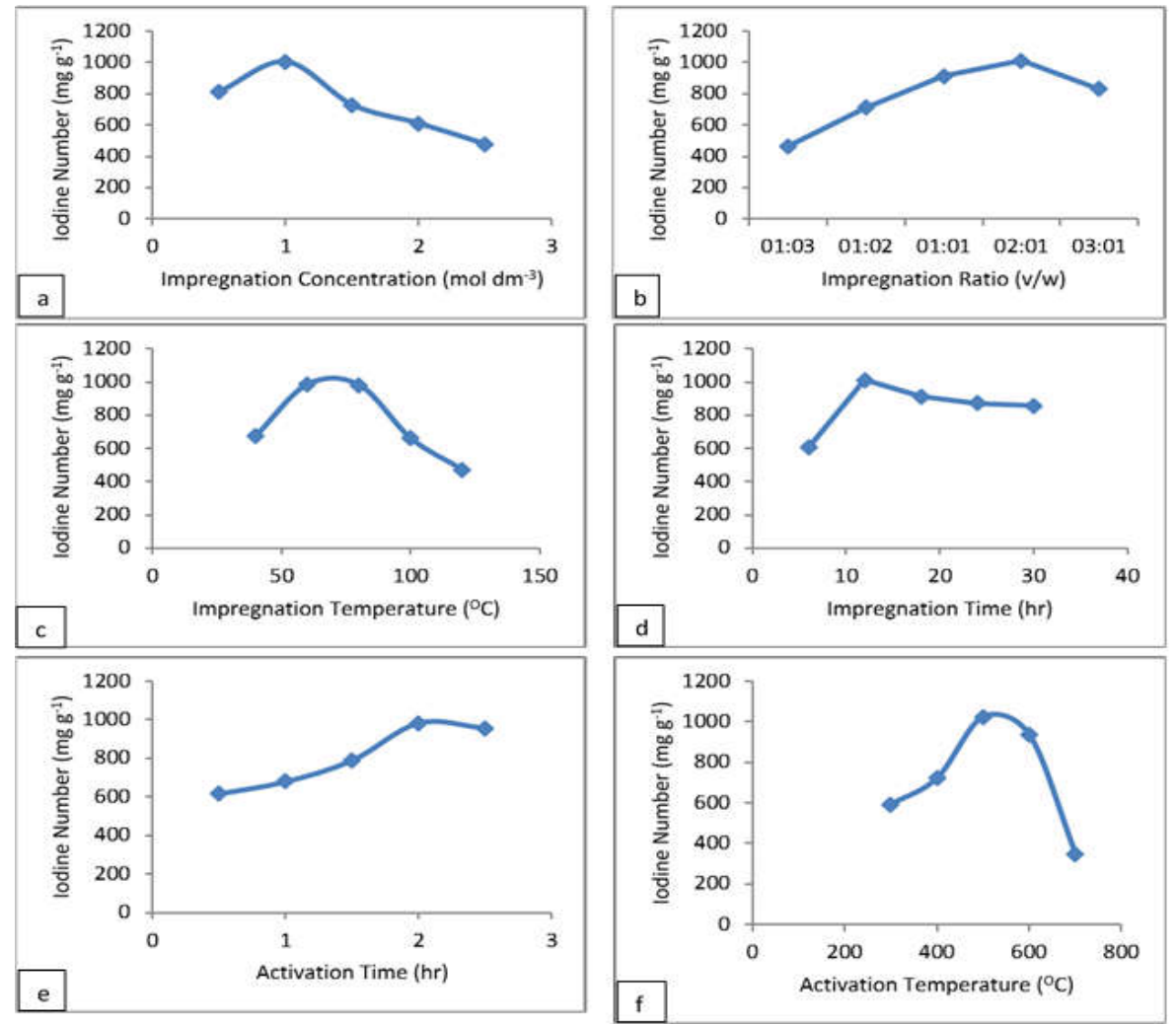

Fig. 1Effect of (a) different concentration of activating agent $\left(\mathrm{ZnCl}_{2}\right)$ (b) impregnation ratio (c) impregnation temperature (d) impregnation time (e) activation temperature and (f) activation time on the iodine adsorption capacity of groundnut shell activated charcoal

Effect of impregnation time: Iodine adsorption efficiency of GAC increased with a corresponding increase in the impregnation time until equilibrium was attained at $12 \mathrm{hr}$. (Fig. 1d). At this time, the porous pores might have been saturated with the activating agent (Subramani and Revathi, 2015). When the impregnation time was extended beyond the critical time, there was no significant change in the iodine adsorption capacity of the test adsorbent, indicating that there were no more porous networks for the activating agent to diffuse.
Effect of activation temperature: The iodine number increased progressively with an increase in the activation temperature, and then decreased as the temperature exceeded $500{ }^{\circ} \mathrm{C}$ (Fig. 1e). Increase in temperature promoted chemical changes that might have occurred in the precursor, resulting to the formation of more pores ready for adsorption at lower temperature. As the critical value was exceeded, there was a decrease in iodine number. This could be attributed to the excessive carbon burnt-off at higher 
temperature resulting to the widening of pore diameters and collapse of pore walls (Alzaydien, 2016; Mopoung et al., 2015; Saka, 2012).

Effect of activation time: Adsorption efficiency of GAC increased with a corresponding increase in the activation time before equilibrium was attained (Fig. 1f). As the pyrolysis time increases, there seemed to be opening of pore walls for adsorption. The rate of iodine adsorption increased until optimum time of $2 \mathrm{hr}$ was reached, and then started decreasing when the activation time was extended to $2.5 \mathrm{hr}$. This could be connected with collapse of surface areas available for adsorption at longer time (Saka, 2012).

Physicochemical properties of GSC and GAC: The physicochemical properties of the GSC and GAC were compared in Table 1. The GAC had a lower yield compared to GSC. Carbonization and activation at higher temperature could have caused that since more volatiles were expected to be released and more carbon converted into ash. The corresponding effect could have led to an increased porosity and surface area of GAC (Abdul-Khalil et al., 2013). High density charcoals had been adjudged to be highly effective for water treatment (Sivakumar et al., 2012) as it helps to improve the filtration rate by forming an even cake on the filter surface (Elelu et al., 2019). Charcoals high in density had been proved to be effective in water treatment (Sivakumar et al., 2012). The bulk density of GAC had the same value $\left(0.48 \mathrm{~g} \mathrm{~cm}^{-1}\right)$ with a charcoal activated with $10 \% \mathrm{Na}_{2} \mathrm{SO}_{4}$ but lower than the values reported for the other charcoals prepared with other activating agent (Sivakumar et al., 2012). It was also lower than $0.59 \mathrm{~g} \mathrm{~cm}^{-1}$ reported for coconut shell activated charcoal (Gawande and Kaware).

Table 1 Results of characterization of groundnutshell charcoal (GSC) and groundnut shell activated charcoal (GAC)

\begin{tabular}{lll}
\hline Property & GSC & GAC \\
\hline Yield $(\%)$ & $78.35 \pm 2.04$ & $67.36 \pm 2.16$ \\
Fixed carbon & $83.07 \pm 1.88$ & $80.56 \pm 1.67$ \\
Volatile matter & $12.86 \pm 0.76$ & $15.70 \pm 1.21$ \\
Ash content $(\%)$ & $2.49 \pm 0.06$ & $3.10 \pm 0.02$ \\
Moisture content $(\%)$ & $7.17 \pm 0.09$ & $2.60 \pm 0.01$ \\
Bulk density $\left(\mathrm{g} \mathrm{cm}^{-3}\right)$ & $0.82 \pm 0.01$ & $0.48 \pm 0.00$ \\
Iodine number $\left(\mathrm{mg} \mathrm{g}^{-1}\right)$ & $639 \pm 4.86$ & $1006 \pm 7.23$ \\
Surface area $\left(\mathrm{m}^{2} \mathrm{~g}^{-1}\right)$ & $522 \pm 4.45$ & $1005 \pm 11.48$ \\
Pore volume $\left(\mathrm{cm}^{3} \mathrm{~g}^{-1}\right)$ & $0.33 \pm 0.00$ & $0.77 \pm 0.01$ \\
Pore size $(\mathrm{nm})$ & $0.41 \pm 0.02$ & $0.80 \pm 0.02$ \\
Porosity $(\%)$ & $49.79 \pm 1.89$ & $96.30 \pm 3.73$ \\
\hline
\end{tabular}

Activated charcoal with lower moisture content has been reported to have more adsorption efficacy (Elelu et al., 2019). Results in Table 1 further showed that moisture content was reduced after the char was activated and carbonized; suggesting that more pores had been introduced into the carbon network (Hidayat and Sutrisno, 2017). The moisture content of the GAC revealed that it would be more effective than activated charcoal from agricultural wastes (Sivakumar et al., 2012), which ranged from 3.12 to $4.12 \%$ and reported for Borassus aethiopum shells activated charcoal where $8.96 \%$ was reported (Jacob et al., 2017) but observed to be less superior to $0.5 \%$ reported for coconut shell activated charcoal (Gawande and Kaware, 2017). Adsorbent with lower moisture content demands for lower quantity during treatment processes (Sivakumar et al., 2012). Ash is an indication of inorganic constituent; therefore charcoal with low ash (higher proportion of carbon) could be used effectively to remove inorganic contaminants in wastewater (Hidayat and Sutrisno, 2017; Jacob et al., 2017; Siakumar et al., 2012). Ash content of GAC in this study was less effective than $1.9 \%$ and $1.88 \%$ found in bagasse activated charcoal (Boonpoke et al., 2011) and coconut shell activated charcoal (Gawande and Kaware, 2017), respectively but was better than $4.01 \%$ reported for Borassus aethiopum shells activated charcoal (Jacob et al., 2017). It fell within the values $(2.7$ to $17.5 \%)$ determined in some agricultural wastes activated with different reagents (Sivakumar et al., 2012). The volatile matter of GSC was lower than that of GAC while fixed carbon was greater. This is expected because carbonization temperature promoted the release of volatiles from breaking of bonds in organic matrices (Hidayat and Sutrisno, 2017). GAC had high fixed carbon and low ash content which are the factors favourable to its utilisation in production of highly effective activated charcoal (Elelu et al., 2019). Activated charcoal functions by the adhesion of substances to the pore walls. The greater the available surface area, the better the adsorption efficiency (Ajala et al., 2015). The surface area obtained for GAC was larger than that of GSC and was within the range of $500-1500 \mathrm{~m}^{2} \mathrm{~g}^{-1}$ specification of activated carbon approved for water purification (Reza et al., 2020; Morlay et al., 2019). The activating agent could have caused swelling of the molecular structure of the precursor cellulose resulting in the breaking of bonds during activation and carbonization (Saka, 2012) with an improved surface area. The value reported in this study was within the range of $718-1018 \mathrm{~m}^{2} \mathrm{~g}^{-1}$ for water treatment charcoals produced from some local materials (Yusufu et al., 2012) and $532-1018 \mathrm{~m}^{2} \mathrm{~g}^{-1}$ in activated charcoal from some agric wastes (Sivakumar et al., 2012). The value was higher than $791.56 \mathrm{~m}^{2} \mathrm{~g}^{-1}$ determined in granulated activated charcoal (Siong et al., 2013) $435.1 \mathrm{~m}^{2} \mathrm{~g}^{-1}$ in coconut shell activated charcoal (Gawande and Kaware, 2017), and $923 \mathrm{~m}^{2} \mathrm{~g}^{-}$ 1 and $927 \mathrm{~m}^{2} \mathrm{~g}^{-1}$ determined in activated charcoals produced from bagasse and rice husk (Boonpoke et al., 2011), respectively. Furthermore, the porous 
properties showed that GAC exhibited type I adsorption isotherm according to IUPAC classification (Reza et al., 2020; Hidayat and Sutrisno, 2017), indicating the formation of micro-porous charcoal. The pore volume as observed in the GAC was higher compared to $0.53 \mathrm{~cm}^{3} \mathrm{~g}^{-1}$ and $0.56 \mathrm{~cm}^{3} \mathrm{~g}^{-1}$ determined respectively, in bagasse and rice husk activated charcoals (Boonpoke et al., 2011) while the pore size was consistent with $0.80 \mathrm{~nm}$ determined in both the bagasse and rice husk activated charcoals (Boonpoke et al., 2011). The pore size indicates that the charcoal is suitable for the adsorption of adsorbates (Sivakumar et al., 2012). GAC porosity agreed well with $96.22 \%$ determined in rice husk-based activated charcoal but lower than $99.19 \%$ determined in bagasse-based activated charcoal (Boonpoke et al., 2011).

The iodine number is an indication of the available surfaces for adsorption in an adsorbent (Saka, 2102). A charcoal with higher iodine number has a better adsorption capacity (Gawande and Kaware, 2017). The iodine number in this study was higher than 942 $\mathrm{mg} \mathrm{g}^{-1}$ in coconut shell activated charcoal (Gawande and Kaware, 2017) and 828.39 - $995.38 \mathrm{mg} \mathrm{g}^{-1}$ determined in activated charcoals produced from some local raw materials (Yusufu et al., 2012) but was within $438-1024 \mathrm{mg} \mathrm{g}^{-1}$ determined by Sivakumar $e t$ al., (2012). Iodine number of GAC denotes that it had excellent adsorptive properties, hence, can be used for adsorption of organic and heavy metal pollutants (Elelu et al., 2019).

Scanning electron microscopy and X-ray Spectroscopy: Scanning electron micrographs (Fig. 2) showed that the surface morphologies of un-activated groundnut shell charcoal (GSC) was intact, relatively organized without any pores except, some cracks. As compared to the GSC image (Fig. 2a), the GAC image (Fig. 2b) had several clear and visible pores and quite irregular cavities due to the release of volatiles within the microstructure as a result of activation, due to this, GAC possessed higher surface area (Abdul-Khalil et al., 2013). Also noticeable on the external surface are numerous cracks and small pits, indicating the interaction of the activating agent with the precursor during carbonization leading to the product with large surface area and porous structure (Abdul-Khalil et al., 2013; Sivakumar et al., 2012). The observed white spheres in the GAC micrograph (Fig. 2b) are likely to be zinc ions which were trapped in the carbon crystal lattices. This was further corroborated by the result of EDS, which showed very high zinc content in the GAC (Table 2), which was due to the use of $\mathrm{ZnCl}_{2}$ as the activating agent. The presence of rough and microporous structure which may offer more adsorption sites in the GAC and alteration in the surface morphology of the precursor confirmed that GAC was chemically modified. Figure 3 shows the X-ray spectra of the GSC and GAC revealing their elemental compositions. There was a decrease in the elemental content of carbon after activation and carbonization. This observation is expected since activation with $\mathrm{ZnCl}_{2}$ caused decomposition of carbon (Mopoung et al., 2015) to form ash.
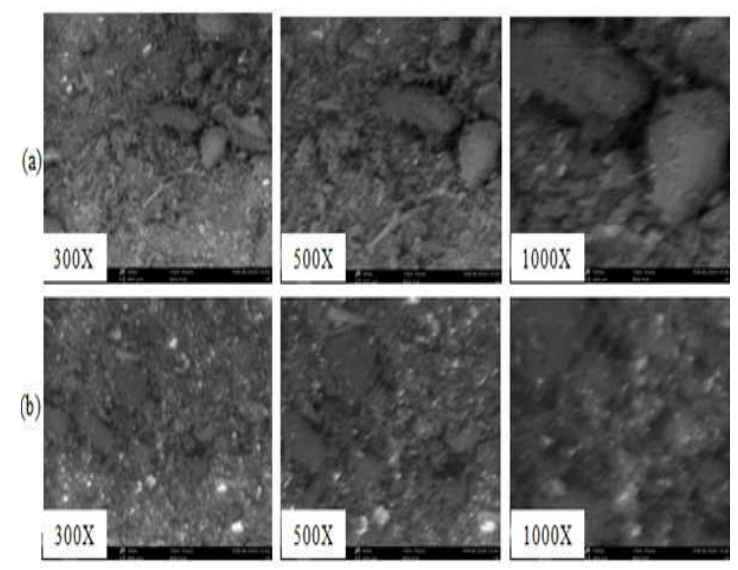

Fig. 2 Micrographs of (a) un-activated and (b) activated groundnut shell-based charcoal at $300 \mathrm{X}, 500 \mathrm{X}$ and $1000 \mathrm{X}$ magnifications.

(a)

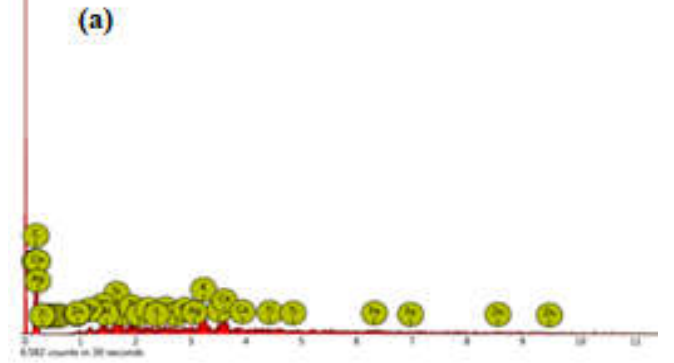

(b)

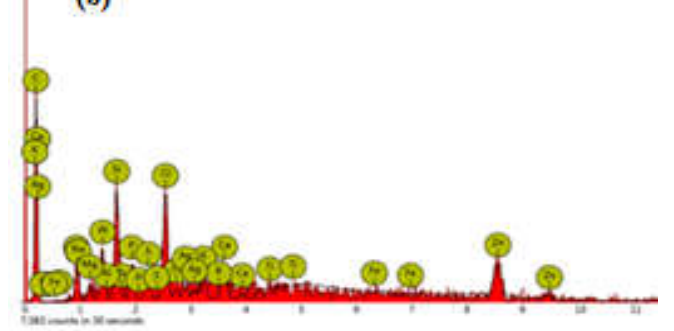

Fig. 3 X-ray spectra of (a) un-activated groundnut shell charcoal (b) groundnut shell-based activated charcoal showing the elemental compositions.

Other principal elements present at the surface were silicon, phosphorus, sodium, and potassium with their atomic concentrations decreasing after activation (Table 2). The high proportion of these elements in GAC limit its adsorption capacity to uptake the metal ions of the elements in aqueous media (Elelu et al., 2019). However, there was an increased in the atomic 
concentration of zinc and chlorine after the activation. This is expected since zinc chloride was used as activating agent which was difficult to wash out completely after the activation and carbonization processes.

Table 2 Results of the elemental composition of the groundnutshell charcoal (left) and groundnut shell activated charcoal (right).

\begin{tabular}{|c|c|c|c|c|c|c|c|c|c|}
\hline $\begin{array}{l}\text { Element } \\
\text { Number }\end{array}$ & $\begin{array}{l}\text { Element } \\
\text { Symbol }\end{array}$ & $\begin{array}{l}\text { Element } \\
\text { Name }\end{array}$ & $\begin{array}{l}\text { Atomic } \\
\text { Conc. }\end{array}$ & $\begin{array}{l}\text { Weight } \\
\text { Conc. }\end{array}$ & $\begin{array}{l}\text { Element } \\
\text { Number }\end{array}$ & $\begin{array}{l}\text { Element } \\
\text { Symbol }\end{array}$ & $\begin{array}{l}\text { Element } \\
\text { Name }\end{array}$ & $\begin{array}{l}\text { Atomic } \\
\text { Conc. }\end{array}$ & $\begin{array}{l}\text { Weight } \\
\text { Conc. }\end{array}$ \\
\hline 19 & $\mathrm{~K}$ & Potassium & 13.99 & 21.13 & 30 & $\mathrm{Zn}$ & Zinc & 20.46 & 39.96 \\
\hline 6 & $\mathrm{C}$ & Carbon & 43.13 & 20.01 & 17 & $\mathrm{Cl}$ & Chlorine & 10.15 & 10.75 \\
\hline 20 & $\mathrm{Ca}$ & Calcium & 9.47 & 14.66 & 6 & $\mathrm{C}$ & Carbon & 27.39 & 9.83 \\
\hline 47 & $\mathrm{Ag}$ & Silver & 2.25 & 9.38 & 14 & $\mathrm{Si}$ & Silicon & 9.71 & 8.15 \\
\hline 14 & $\mathrm{Si}$ & Silicon & 8.14 & 8.83 & 11 & $\mathrm{Na}$ & Sodium & 10.24 & 7.03 \\
\hline 15 & $\mathrm{P}$ & Phosphorus & 4.12 & 4.93 & 47 & $\mathrm{Ag}$ & Silver & 1.74 & 5.61 \\
\hline 13 & $\mathrm{Al}$ & Aluminium & 4.46 & 4.64 & 13 & $\mathrm{Al}$ & Aluminium & 5.55 & 4.47 \\
\hline 17 & $\mathrm{Cl}$ & Chlorine & 2.89 & 3.95 & 20 & $\mathrm{Ca}$ & Calcium & 3.48 & 4.17 \\
\hline 12 & $\mathrm{Mg}$ & Magnesium & 3.64 & 3.41 & 15 & $\mathrm{P}$ & Phosphorus & 3.26 & 3.02 \\
\hline 16 & $\mathrm{~S}$ & Sulphur & 2.60 & 3.22 & 16 & $\mathrm{~S}$ & Sulphur & 2.52 & 2.42 \\
\hline 26 & $\mathrm{Fe}$ & Iron & 1.21 & 2.62 & 19 & K & Potassium & 1.98 & 2.31 \\
\hline 11 & $\mathrm{Na}$ & Sodium & 2.74 & 2.43 & 12 & $\mathrm{Mg}$ & Magnesium & 2.53 & 1.84 \\
\hline 8 & $\mathrm{O}$ & Oxygen & 0.70 & 0.43 & 8 & $\mathrm{O}$ & Oxygen & 0.51 & 0.25 \\
\hline 7 & $\mathrm{~N}$ & Nitrogen & 0.66 & 0.36 & 7 & $\mathrm{~N}$ & Nitrogen & 0.46 & 0.19 \\
\hline 22 & $\mathrm{Ti}$ & Titanium & 0.00 & 0.00 & 22 & $\mathrm{Ti}$ & Titanium & 0.00 & 0.00 \\
\hline 30 & $\mathrm{Zn}$ & Zinc & 0.00 & 0.00 & 26 & $\mathrm{Fe}$ & Iron & 0.00 & 0.00 \\
\hline
\end{tabular}

Infra-red spectroscopy: Chemical reactivity of functional groups at the surface of activated charcoals gives an understanding into their adsorption efficiency (Abdul-Khalil et al., 2013; Saka, 2012). A comparison of the FT-IR spectra of GSC and GAC (Fig. 4) showed that new peaks at 2907.3 and $2653.6 \mathrm{~cm}^{-1}$ assigned to $\mathrm{C}-\mathrm{H}$ stretching groups of alkanes and aldehydes (Abdul-Khalil et al., 2013; Saka, 2012), respectively, which were absent in the GSC appeared in the GAC spectrum. Conversely, $\mathrm{O}-\mathrm{H}$ stretching vibration at a wave number of $3246.5 \mathrm{~cm}^{-1}$ (Abdul-Khalil et al., 2013 ) in the GSC was completely absent in the GAC.
This might be due to the removal of oxygencontaining functional group at high carbonization temperature. Modification of the precursor with the activating agent and carbonization removed the functional groups at $1364.2 \mathrm{~cm}^{-1}$ attributed to aromatic groups stretching vibration (Wu et al., 2020), 1233.7 $\mathrm{cm}^{-1}$ due to $\mathrm{C}-\mathrm{O}$ stretching of alcohols, phenols, esters or ethers (Saka, 2012), and P-O stretching characteristic absorption peak at $1159.2 \mathrm{~cm}^{-1}$ (Pavia et al., 2015) in the GAC. These groups might have been converted into volatiles leading to the formation of more pores and increase in porosity.

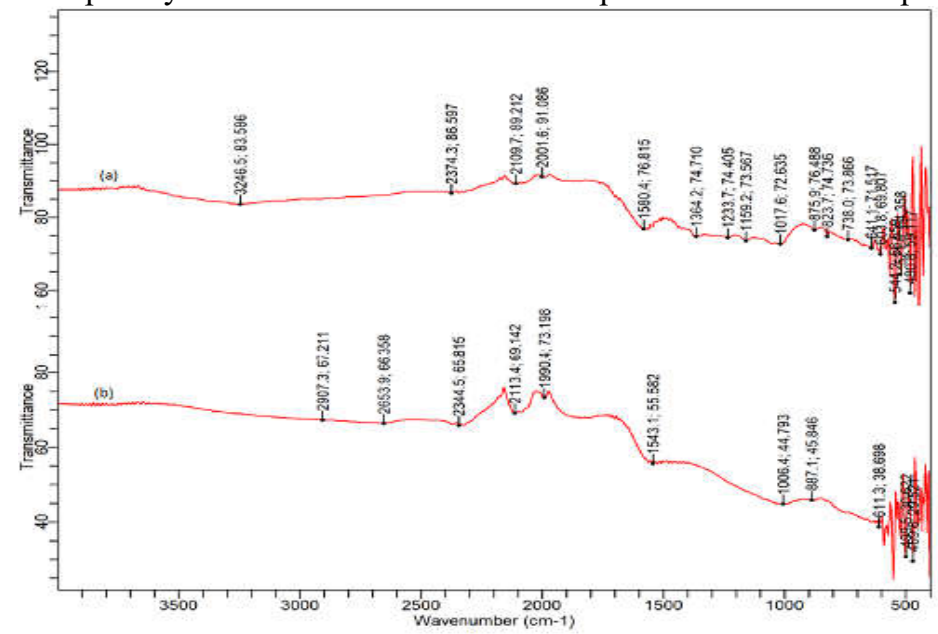

Fig 4IR spectra of (a) un-activated groundnut shell charcoal and (b) groundnut shell-based activated charcoal

The visible weak band at $2374.3 \mathrm{~cm}^{-1}$ corresponding to the stretching vibration of C-O (Saka, 2012; AbdulKhalil et al., 2013; Pavia et al., 2015) in the GSC spectrum (Fig. 4a) was shifted substantially to 2346.5 $\mathrm{cm}^{-1}$ as observed in the GAC spectrum (Fig. 4b). The original strong and broad absorption band at 1580.4 $\mathrm{cm}^{-1}$ in the GSC characteristics of the ring vibration commonly found in large aromatic skeletons of carbonaceous materials (Saka, 2012) shifted to a lower frequency $1543.1 \mathrm{~cm}^{-1}$ in the GAC spectrum. Also in the GSC spectrum, the absorption bands between 2374.3 and $2001.6 \mathrm{~cm}^{-1}$ characteristic of $\mathrm{C} \equiv \mathrm{C}$ stretch 
in alkynes (Saka, 2012; Pavia et al., 2015) were shifted to $2344.5,2113.4$ and $1990.1 \mathrm{~cm}^{-1}$, respectively, in the GAC spectrum. Peaks at $1017.6 \mathrm{~cm}^{-1}$ assigned to asymmetric stretching of $\mathrm{Si}-\mathrm{O}$ bond (Pavia et al., 2015) was equally shifted to $1006.4 \mathrm{~cm}^{-1}$ and peak at $875.9 \mathrm{~cm}^{-1}$ assigned to aldehyde stretching vibration (Pavia et al., 2015) shifted to a higher wave number $\left(887.1 \mathrm{~cm}^{-1}\right)$ in the GAC. The disappearance of some functional groups in GAC and change in the absorption bands are indication that surface structural modification had taken place during activation and carbonization.

Conclusion: Groundnut shell was used to produce activated charcoal using zinc chloride as an activating agent. The properties of the adsorbent such as large surface area, high iodine absorption capacity, low ash content (high carbon), and high degree of porosity, which are favourable factor for its utilization for activated charcoal production revealed that it had an improved adsorption comparable to those of high performance adsorbents. Based on the results of the characterization, this carbonized biomass could be used in the treatment of wastewater, and adsorption of pesticides, dyes and heavy metals.

Acknowledgments: This research was proudly supported and sponsored by Tertiary Education Trust Fund (TETFund) of the Federal Republic of Nigeria, through the institution-based research grant.

\section{REFERENCES}

Abdul-Khalil, HPS; Jawaid, M; Firoozian, P; Rashid, U; Islam, A; Akil HMd (2013). Activated carbon from various agricultural wastes by chemical activation with $\mathrm{KOH}$ : Preparation and characterization. J. Biobased Mater. Bioener. $7(5)$.

Abraham, FA; Thenmozhi, R; Sivakumar, M; Sivakumar, K; $\quad$ Sasikumar, G; Thamaraimuthuayyanraj, S (2018). Waste water treatment unit using activated charcoal. Intl. Res. J. Engr. Tech. 5(3): 312-315.

Ajala, LO; Onwukeme, VI; Oji, CO; Ejiagha, MC (2020). Sustainable utilization of rice husk activated charcoal as wastewater decontaminant. In: Tüzemen S (ed) New Insights into Physical Science Vol. 2 Book Publisher International, India. pp.111-125.

Alzaydien, AS (2016). Physical chemical and adsorptive characteristics of local oak sawdust based activated carbons. Asian J. Sci. Res. 9: 4556.
Amirza, MAR; Adib, MMR; Hamdan, R(2017). Application of agricultural wastes activated carbon for dye removal - An overview. MATEC Web. Conf. 103.

Ani, JU; Akpomie, KG; Okoro, UC; Aneke, LE; Onukwuli, OD; Ujam, OT (2020). Potentials of activated carbon produced from biomass materials for sequestration of dyes, heavy metals, and crude oil components from aqueous environment. Appl. Wat. Sci. 10(69).

Boonpoke, A; Chiarakorn, S; Laosiripojana, N; Towprayoon, S; Chidthaisong, A (2011). Synthesis of activated carbon and MCM-41 from bagasse and rice husk and their carbon dioxide adsorption capacity. J. Sust. Energ. Environ. 2:77 -81 .

Elelu, S; Adebayo, GB; Abduls-Salam, N; Iriowen, EM (2019). Preparation and characterization of adsorbents from physic nut plant (Jatropha curcas L.). The Chemist, 91(2): 42-49.

Gawande, PR; Kaware, JP (2017). Characterization and activation of coconut shell activated carbon. Intl. J. Eng. Sci. Inv. 6(11): 43-49.

Gokhale, NA; Trivedi, NS; Mandavgane, SA; Kulkarni, BD (2020). Biomass ashes as potent adsorbent for pesticide: prediction of adsorption capacity by artificial neural network. Intl. J. Environ. Sci. Tech. 17: 3209-3216.

Hidayat A, Sutrisno B (2017). Comparison on pore development of activated carbon produced by chemical and physical activation from palm empty fruit bunch. IOP Conf. Series: Mat. Sci. Eng. 162.

Ijaola, OO; Ogedengbe, K; Sangodoyin, AY (2013). On the efficacy of activated carbon derived from bamboo in the adsorption of water contaminants. Intl. J. Eng. Inv. 2(4): 29-34.

Jacob, AG; Okunola, OJ; Uduma, AU; Tijjani, A; Hamisu S (2017). Treatment of waste water by activated carbon developed from Borassus aethiopum. Nig. J. Mat. Sci. Engr. 6(1): 103-107.

Mansour, RA; Shahawy, AE; Attia, A; Beheary, MS (2020). Brilliant green dye biosorption using activated carbon derived from guava tree wood. $J$. Ind. Engr. Chem. https://doi.org/10.1155/2020/8053828 
Marichelvan, MK; Azhagurajan, A (2018). Removal of mercury from effluent solution by using banana corm and neem leaves activated charcoal. Environ. Nanotechnol. Monit. Manage. 10: 360365 .

Mopoung, S; Moonsri, P; Palas, W; Khumpai, S (2015). Characterization and properties of activated carbon prepared from tamarind seeds by $\mathrm{KOH}$ activation for $\mathrm{Fe}$ (III) adsorption from aqueous solution. The Sci. World J. http://dx.doi/10.1155/415961

Morlay, C; Gasperi, J; Guillossou, R; Mailler, R; Le Roux, J; Rocher, V; Vulliet, E; Nauleau, F (2019). Organic micropollutants in a large wastewater treatment plant: What are the benefits of an advanced treatment by activated carbon adsorption in comparison to conventional treatment? Chemosphere 218: 1050-1060.

Olagunju, EO; Ajala, LO; Farombi, AG (2105). Sustainable utilization of rice husk activated charcoal through phytoremediation. Phy. Sci. Intl. $J .5(2): 81-87$.

Özsin, G; Kılıç, M; Apaydın-Varol, E; Pütün, AE(2019). Chemically activated carbon production from agricultural waste of chickpea and its application for heavy metal adsorption: Equilibrium, kinetic, and thermodynamic studies. Appl. Wat. Sci.9: 56.

Pavia, DL; Lampman, GM; Kriz, GS; Vyvyan, JR(2015). Introduction to spectroscopy (5th edn). Cengage Learning, USA.

Reza, MS; Hasan, ABM; Afroze, K; Abu-Bakar, MS; Taweekun, J; Azad, AK (2020). Analysis on preparation, application, and recycling of activated carbon to aid in Covid-19 protection. Intl. J. Integ. Engr.12 (5): 233-244.
Saka, C (2012). BET, TG-DTG, FT-IR, SEM, iodine number analysis and preparation of activated carbon from acorn shell by chemical activation with $\mathrm{ZnCl}_{2}$. J. Anal. Appl. Pyrol. 95: 21-24.

Siong, YK; Idris, AJ; Atabaki, AMM (2013). Performance of activated carbon in water filters. Assessed on 17th February, 2020 available at https://www.researchgate.net/publication/23406 $\underline{0484 m m}$

Sivakumar, V; Asaithambi, M; Sivakumar, P (2012). Physic-chemical and adsorption studies of activated carbon from agricultural wastes. $A d v$. Appl. Sci. Res. 3(1): 219-226.

Subramani, T; Revathi, PK (2015). Production of activated carbon from agricultural raw waste. $J$. Eng., 5(5): 54-63.

Tak, B; Tak, B; Kim, Y; Park, Y; Yoon, Y; Min, G (2015). Optimization of colour and COD removal from livestock wastewater by electrocoagulation process: Application of Box-Behnken Design (BBD). J. Ind. Eng. Chem. 28: 307-315.

Wang, J; Wu, F; Wang, M; Qui, N; Liang, Y; Fang, S; Jiang, S(2010). Preparation of activated carbon from a renewable agricultural residue of pruning mulberry shoot. Afr. J. Biotechnol. 9(19): 27622767.

Wu, W.; Zhang, X.; Yang, J.; Li, J; Li, X (2020). Facial preparation of oxygen-rich activated carbon from petroleum coke for enhancing methylene blue adsorption. Carbon Lett. 30: 627636.

Yusufu, MI; Ariahu, CC; Igbabul, BD (2012). Production and characterization of activated carbon from selected local raw materials. Afr. J. Pure Appl. Chem. 6(9):123-131. 